\title{
Population Study of Proboscis Monkey (Nasalis larvatus) on the Islands of Pulau Bakut and Pulau Curiak in South Kalimantan, Indonesia
}

\author{
Amalia Rezeki, Zainudin, Elliott James Ong, Charles CC Lee, Tim Roberts
}

The proboscis monkey (Nasalis larvatus) is categorised as Endangered under the IUCN Red List with a decreasing population trend [1]. The major threat to their survival is habitat destruction from logging and land clearance for agriculture and settlements. As of the year 2000, only $39 \%$ of suitable habitat remained with only $15 \%$ of this habitat included under conservation areas. The percentage of remaining habitat has likely decreased since then due to increased deforestation in Borneo. Although proboscis monkeys are protected by Indonesian law and are listed in CITES Appendix I, weak law enforcement coupled with a lack of awareness, political support and funding hampers the effective conservation of this species [2].

Named for the uniquely large and elongate noses that the males possess [3], the proboscis monkey, proboscis monkeys are large, arboreal primates from the subfamily Colobinae [2]. The species is sexually dimorphic with males significantly larger in size and sporting a larger nose than females [4]. Endemic to the island of Borneo, they are found in coastal and inland areas of lowland forest, mangroves, riverine forest, peat swamp and freshwater swamp forests in Sabah, Sarawak (Malaysia), Brunei and Kalimantan (Indonesia).

Kalimantan boasts the largest population of proboscis monkeys, where they are found in at least 153 locations with population sizes ranging from more than 1000 to less than 100 [2]. Although larger than those in Malaysian Sabah and Sarawak, the proboscis monkey populations in Kalimantan are scattered due to habitat fragmentation and most of these populations have not been well-studied to date. More data on these isolated populations is needed to better understand the current situation of the proboscis monkey on a larger scale. In South Kalimantan, the proboscis monkey is heralded as an official mascot and there are 35 locations in the area where proboscis monkeys are known to inhabit [2], which include the islands of Pulau Bakut and Pulau Curiak in the Barito River, South Kalimantan.

The populations of proboscis monkeys on these two islands were surveyed in 2016 to obtain baseline information on the structure, size and density of the population along with their social structure. Compared to other proboscis monkeys at other sites, the populations inhabiting these two islands have an unusually high population density and unique group structure. The reason behind these observations are likely to do with the unusually small area that these populations inhabit along with the effect of the reintroduction of individuals from external sites into Pulau Bakut. These observations suggest that it is worth investigating the stability and growth of these populations through a more prolonged study, to determine the health of the population as well as to record potentially new behavior associated with avoiding agonistic encounters at high population density. The baseline information was also used to recommend a suitable conservation strategy to improve the health and promote growth of the proboscis monkey populations on the two islands. Conservation measures recommended included increasing habitat connectivity, limiting human disturbance and habitat enhancement efforts to increase plant diversity on the islands.

\section{References}

[1] Meijaard, E., Nijman, V., Supriatna, J., "Nasalis larvatus ssp. Larvatus," IUCN Red List of Threatened Species, 2008.

[2] Meijaard, E., Nijman, V. "Distribution and conservation of the proboscis monkey (Nasalis larvatus) in Kalimantan, Indonesia," Biological Conservation, vol.92, no.1, pp.15-24, 2000. 
[3] Mazlan, N., Abd Rahman, MR., Tingga, RBT., Abdullah, MT., Khan, FAA., "Population genetic analyses of the endangered proboscis monkey from Malaysian Borneo," Folia Primatologica, vol.90, no.3, pp.139-152, 2019.

[4] Yeager, CP. "Proboscis monkey (Nasalis larvatus) social organization: Group structure," American Journal of Primatology, vol 20, no.2, pp.95-106, 1990. 